\title{
G Protein-Coupled Purinergic P2Y Receptor Oligomerization: Pharmacological Changes and Dynamic Regulation
}

\author{
Xiaoqing Guo ${ }^{1}$, Qin $\mathrm{Li}^{1}$, Shulan $\mathrm{Pi}^{1}$, Bo $\mathrm{Hu}^{1}$, Yuanpeng $\mathrm{Xia}^{1}$, and Ling $\mathrm{Mao}^{1}$ \\ ${ }^{1}$ Huazhong University of Science and Technology
}

December 1, 2020

\begin{abstract}
P2Y receptors (P2YRs), a $\delta$ group of rhodopsin-like G protein-coupled receptors (GPCRs), have many essential functions in physiology and pathology, such as platelet aggregation, immune responses, neuroprotective effects, inflammation, and cellular proliferation; thus, they are among the most researched therapeutic targets for use in the clinical treatment of diseases (e.g., clopidogrel, an antithrombotic drug, and Prolacria, a treatment for dry eye). Over the past two decades, GPCRs have been revealed to transmit signals as dimers to increase the diversity of signalling pathways or pharmacological activities. Many studies have frequently confirmed dimerization between P2YRs and other GPCRs due to their functions in cardiovascular and cerebrovascular processes in vivo and in vitro. Recently, some P2YR dimers that dynamically balance physiological functions in the body were shown to be involved in effective signal transduction and exert pathological pharmacological effects. In this review, we summarize the types, pharmacological changes, and active regulators of P2YR-related dimerization. In summary, our review delineates that P2YR-related dimers have new functions and pharmacological activities and maybe a novel direction to improve the effectiveness of medications such as thrombotic events associated with COVID-19.
\end{abstract}

\section{Hosted file}

G Protein-Coupled Purinergic P2Y Receptor Oligomerization.pdf available at https: //authorea.com/users/380459/articles/496437-g-protein-coupled-purinergic-p2y-receptoroligomerization-pharmacological-changes-and-dynamic-regulation

\section{Hosted file}

Table 1.pdf available at https://authorea.com/users/380459/articles/496437-g-proteincoupled-purinergic-p2y-receptor-oligomerization-pharmacological-changes-and-dynamicregulation 


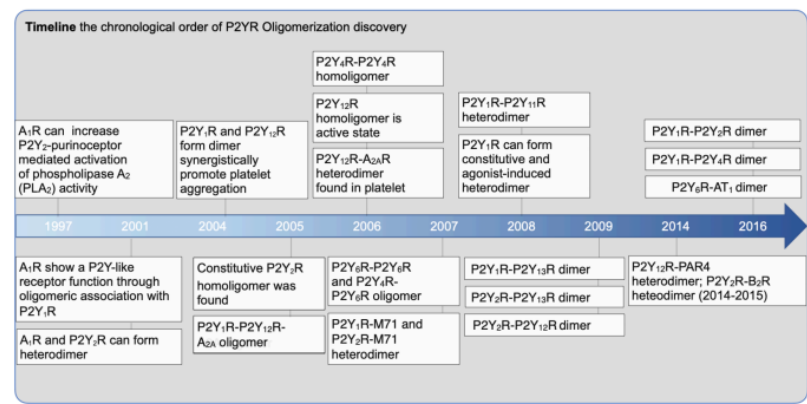

Figure 1. The Chronological Order of P2YR Oligomerization Discovery

$P 2 Y R, P 2 Y$ receptors; MAP kinase, mitogen-activated protein kinase; $A_{1} R$, adenosine $A 1$ receptor; $A_{2 A} R$, adenosine $A_{2 A}$ receptor; $M 71$, olfactory receptor $M 71 ; A T 1$, angiotensin II type receptor. 


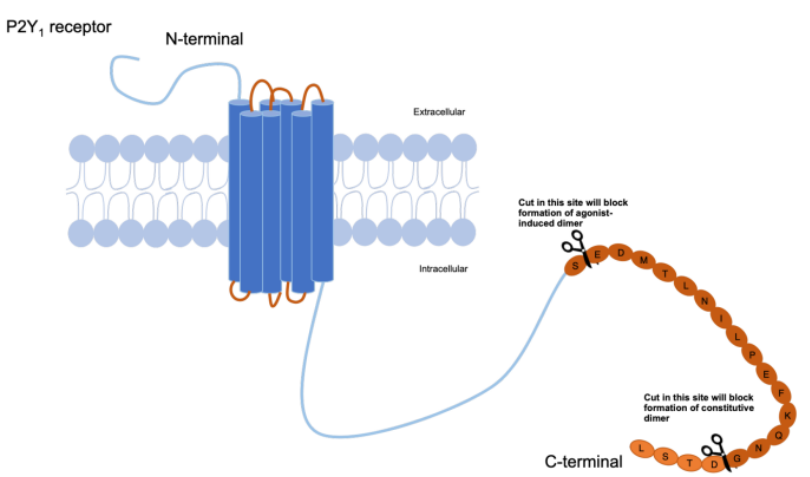

Figure 2. The Key Sequence in the Dimerization for $P 2 Y_{1} R$

Some $\mathrm{P} 2 \mathrm{Y}_{1} \mathrm{R}$ can exists as a homodimer. In resting state, the last four amino acids (DTSL) are important for its constitutive dimerization in the C-terminal. Moreover, the major structure for agonist-induced $\mathrm{P} 2 \mathrm{Y}_{1} \mathrm{R}$ dimerization is the last 19 amino acids (EDMTLNILPEFKQNG) in the C-terminal, which also can regulate receptor internalization. 

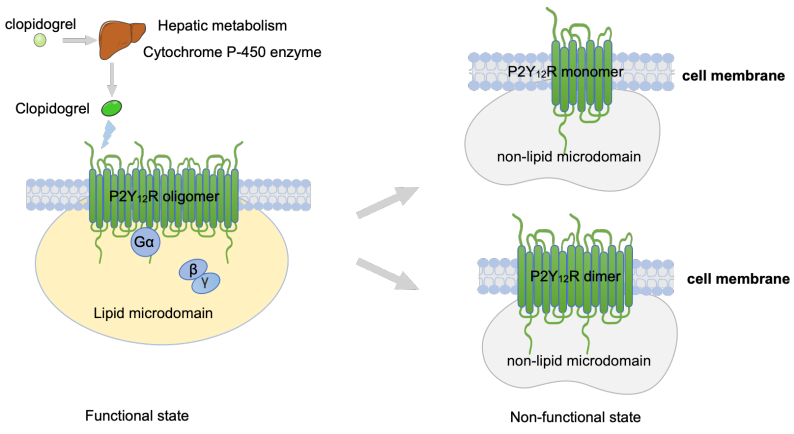

Figure 3. The Possible Active Form and Membrane Location of $P 2 Y_{12} R$

The $\mathrm{P} 2 \mathrm{Y}_{12} \mathrm{R}$ oligomer preferentially associates as functional homooligomers within the lipid raft microdomain of the membrane surface, which is important for its functional activity. The active metabolite of clopidogrel, obtained through liver metabolism, acts on the binding site of oligomers, thereby inhibiting the effect of $P 2 Y_{12} R$. It can separate non- functional dimers and monomers under the effect of Act-Met and reaching a location outside the lipid microdomain. 